\title{
Orthodontic treatment of an impacted dilacerated maxillary incisor: A case report
}

\author{
Paola Cozza*/ Alessandra Marino**/ Roberta Condo***
}

Dilaceration is one of the causes of permanent maxillary incisor eruption failure. It is a developmental distortion of the form of a tooth that commonly occurs in permanent incisors as result of trauma to the primary predecessors whose apices lie close to the permanent tooth germ. We present a case of post-traumatic impaction of a dilacerated central maxillary left incisor in a young patient with a class II malocclusion.

J Clin Pediatr Dent 30(2): 93-98, 2005

\section{INTRODUCTION}

$\mathrm{D}$ ilaceration is one of the causes of permanent maxillary incisor eruption failure and represents a challenge to clinicians. ${ }^{1}$

It is a developmental distortion of the form of a tooth that commonly occurs in permanent incisors as result of trauma to the primary predecessors whose apices lie close to the permanent tooth germ. The new portion of tooth, generally the root, is formed at an angle in relation to the crown portion formed before the injury. ${ }^{2}$

The treatment of dilacerated anterior teeth poses a clinical dilemma because of its difficult position. The chances of failure could be due to ankylosis, external root resorption and root exposure after orthodontic traction. ${ }^{3.4}$ Because of these problems, treatment usually involves surgical removal with subsequent orthodontic treatment to close the space or keep it open until the patient reaches an age when definitive implants or prosthodontic treatments may be used. ${ }^{1}$

However, owing to the esthetic importance of the maxillary incisors, patients and parents always request that such teeth be saved. Surgical exposure followed by orthodontic traction is the solution most widely

\footnotetext{
*Prof. Paola Cozza is a Professor in Orthodontics, Department of Orthodontics, School of Dentistry, University of Rome "Tor Vergata" and in private practice.

**Dr. Alessandra Marino is a research assistant, Department of Orthodontics in the University of Rome "La Sapienza", and in private practice.

***Dr Roberta Condo is an orthodontist in private practice in Rome
}

All correspondence should be sent to: Prof. Paola Cozza, Via Veio 53, 00183 Roma, Italy.

Phone and fax number :0039670474183

E-mail address: p.cozza@flashnet.it adopted to save an impacted dilacerated incisor. Because of the root angulation of the impacted incisor, multiple surgeries complicated orthodontic management, additional periodontal surgery and a comprised gingival margin usually are inevitable. ${ }^{5,6}$

We present a case of post-traumatic impaction of a dilacerated central maxillary left incisor in a young patient with a class II malocclusion.

\section{CASE REPORT}

\section{HISTORY AND INITIAL EXAMINATION}

A 12 year old Caucasian male subject was referred by his general dentist to the orthodontic department of the University of Rome "Tor Vergata" for evaluation. The chief complaint was concern about an unerupted front permanent tooth, which had resulted in an unaesthetic appearance. His dental history revealed a traumatic injury to the primary maxillary left central incisor at age 4 . His mother reported the patient had fallen down on a child's slide; this was followed later by darkening of the tooth.

\section{DIAGNOSIS}

The patient's face was symmetric with a convex type profile. Clinical examination showed a late mixed dentition and the persistence of the primary maxillary left central incisor (Figure 1).

Occlusal analysis revealed a class II molar and canine relationship with an overbite of $4 \mathrm{~mm}$ and an overjet of $4.5 \mathrm{~mm}$. Maxillary and mandibular arches form were well shaped.

\section{RADIOGRAPHIC AND CEPHALOMETRIC EVALUATION}

The panoramic radiograph demonstrated the impaction of the maxillary left central incisor. The incisor was mesially inclined and it was not possible to 


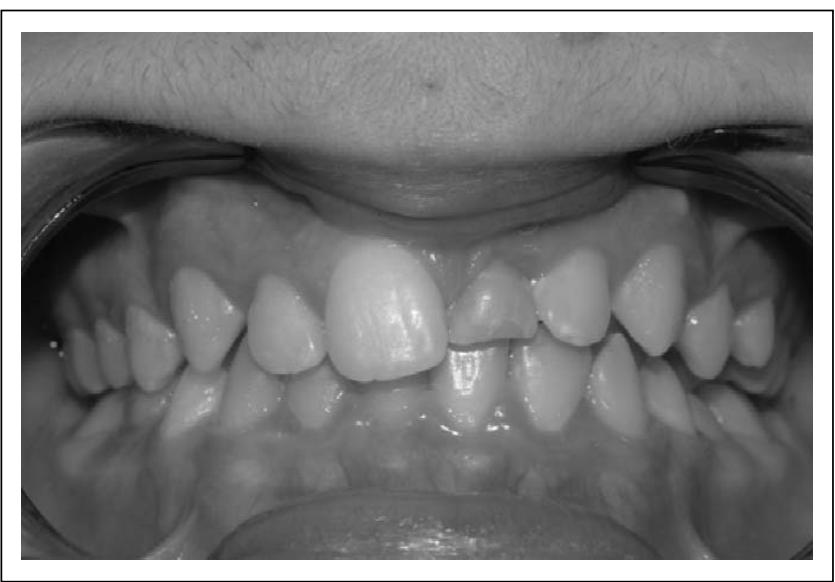

Figure 1. Initial intraoral frontal view
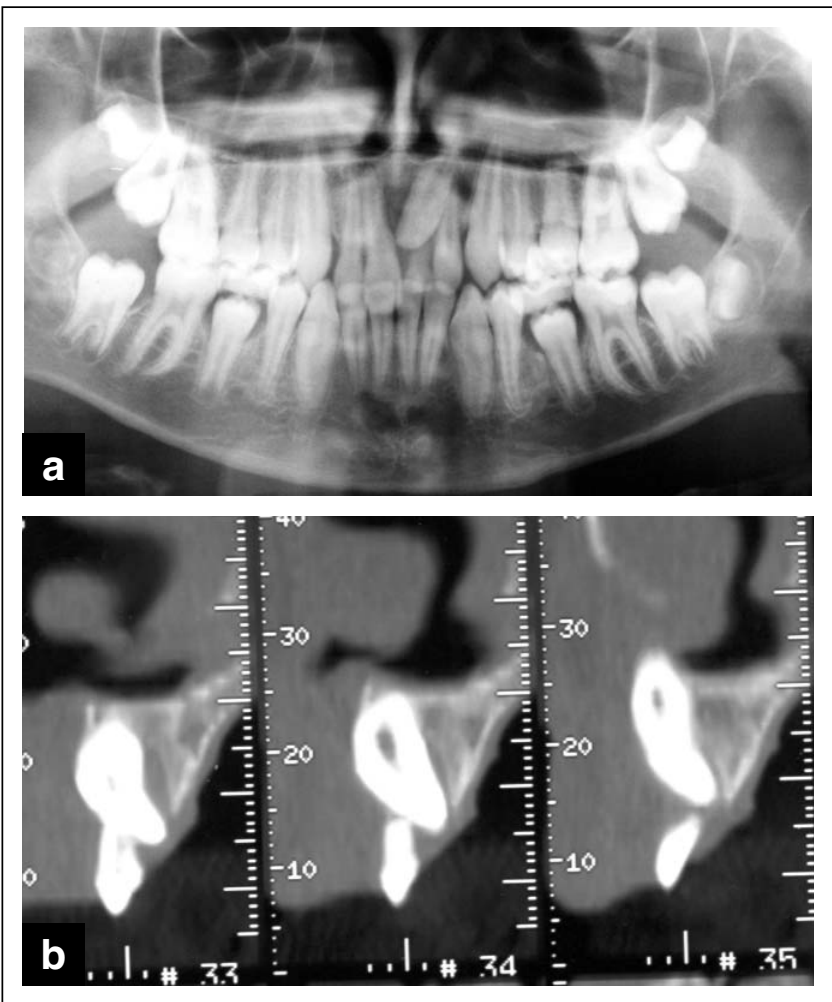

Figure 2. Initial radiographic views: a.: Panoramic view; b.: TC Dentascan

exactly define the root apex (Figure 2a). Subsequently a careful supervision was considered important and a computerized tomography was required.

TC-Dentascan evaluation confirmed the presence of the impacted tooth localized in the body of the premaxilla with a sharp bend at the level of the root's apical third (Figure 2b). The crown-root angle was judged to be about 35 degrees. Therefore the use of TC-Dentascan was essential to show the root dilaceration and focus on potential problems associated with the eruption of such an impacted tooth.

Cephalometric analysis revealed a mild skeletal Class II malocclusion (ANB T0: $4^{\circ}$ ) and a mesofacial

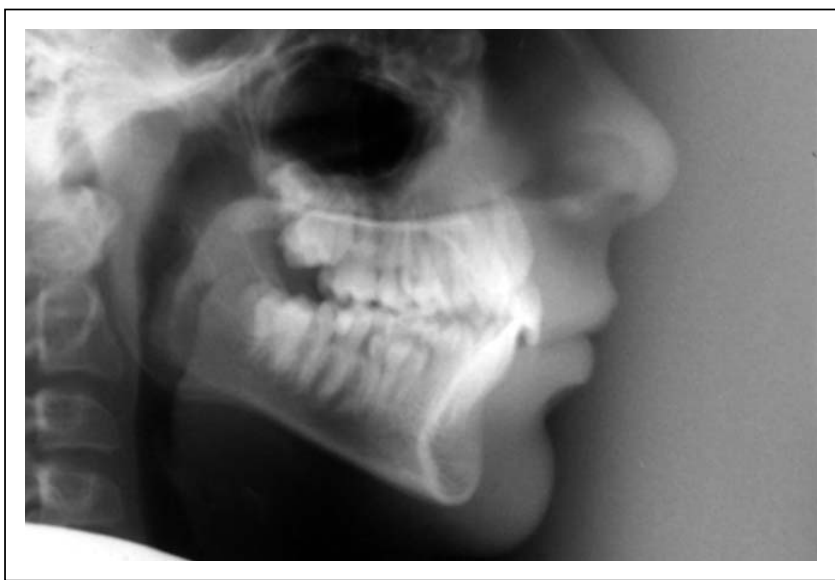

Figure 3. Initial lateral cephalometric radiographic view

pattern (FMA T0: $23^{\circ}$ ). Proper upper and lower incisor inclination. (Figure 3) (Tab.1)

Table 1

\begin{tabular}{lll}
\hline VARIABLES & T0 & T1 \\
\hline SNA angle & $83^{\circ}$ & $81^{\circ}$ \\
SNB angle & $79^{\circ}$ & 80 \\
ANB angle & $4^{\circ}$ & $1^{\circ}$ \\
AoBo mm & $3 \mathrm{~mm}$ & $1 \mathrm{~mm}$ \\
SN mm & $76 \mathrm{~mm}$ & $79 \mathrm{~mm}$ \\
GoGn mm & $66 \mathrm{~mm}$ & $80 \mathrm{~mm}$ \\
FMA angle & $23^{\circ}$ & $23^{\circ}$ \\
SN^GoGn angle & $30^{\circ}$ & $29^{\circ}$ \\
P.Occi^PF & $6^{\circ}$ & $1^{\circ}$ \\
Overjet mm & $4.5 \mathrm{~mm}$ & $2 \mathrm{~mm}$ \\
Overbite mm & $4 \mathrm{~mm}$ & $2 \mathrm{~mm}$ \\
IMPA angle & $95^{\circ}$ & $93^{\circ}$ \\
FMIA angle & $62^{\circ}$ & $64^{\circ}$ \\
INC.SUP.^PF angle & $110^{\circ}$ & $118^{\circ}$ \\
Interincisal angle & $126^{\circ}$ & $122^{\circ}$ \\
ANL angle & $116^{\circ}$ & $146^{\circ}$ \\
UL-LE mm & $-3 \mathrm{~mm}$ & $-3 \mathrm{~mm}$ \\
LL-LE mm & $-2 \mathrm{~mm}$ & $-4 \mathrm{~mm}$ \\
NS^SAr & $125.5^{\circ}$ & $122^{\circ}$ \\
SAr^ArGo & $140^{\circ}$ & $142^{\circ}$ \\
ArGo^GoMe & $129^{\circ}$ & $126^{\circ}$ \\
ArGo^GoGn & $56^{\circ}$ & $56^{\circ}$ \\
NGo^GoMe & $73^{\circ}$ & $70^{\circ}$ \\
$\sum$ & $394.5^{\circ}$ & $390^{\circ}$ \\
\hline
\end{tabular}

\section{TREATMENT OBJECTIVES}

The following treatment objectives were established for this patient:

- guide eruption of the impacted tooth and align it ortodontically;

- achieve good gingival attachment and symmetrical gingival margins for both maxillary central incisors;

- establish class I molar and canine relationship bilaterally and ideal overbite and overjet;

— create a stable functional occlusion. 


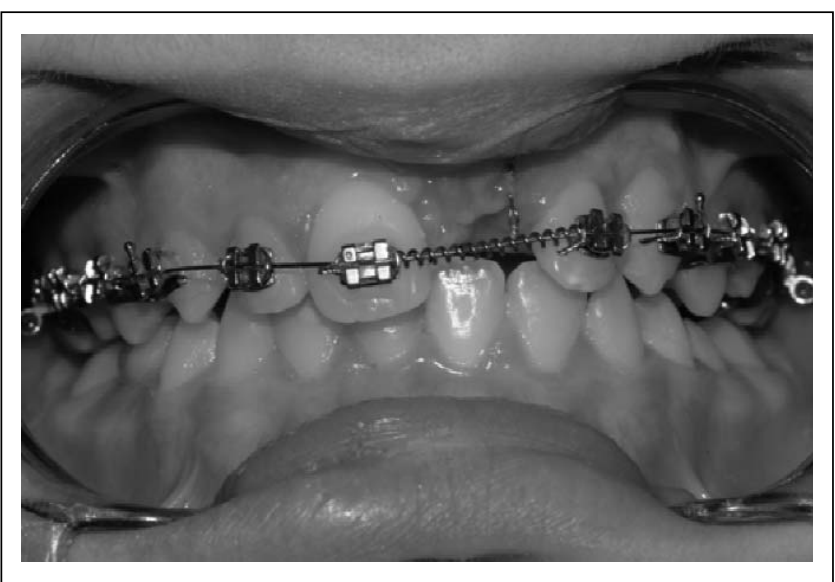

Figure 4. Intraoral frontal view during orthodontic treatment

\section{TREATMENT PLAN}

Molar bands were placed on the maxillary first molars and brackets on the maxillary incisors, excluding the primary one which was extracted.

At the same time cervical headgear was placed to move the molars distally. The patient was instructed to wear the headgear 14 to 16 hours/day.

Once adequate leveling and alignment was accomplished, a $0.018 \times 0.022$-inch stainless wire, with open coil spring in the area of the impacted incisor would normally occupy, was placed for stability.

Subsequently, the patient was referred to an oral surgeon for exposure and button attachment in the impacted incisor with an elastic power chain ligated to it.

Surgical exposure has been performed using a closed eruption technique, in which the raised flap that incorporates attached gingival is fully replaced to its former position. In fact the gingival flap was sutured back in such a way that the bracketed crown was not exposed into the oral cavity. Special care was given to preserve the bone, mucoperiostum and gingival tissues around the crown. The patient returned two weeks later, after soft tissue healing, and the elastic chain was tied with tension to the open coil. (Figure 4) The patient was seen on a monthly basis. Traction was continued for 6 months until the eruption of the left central incisor.

As the tooth moved close to its designated position the button was removed and an orthodontic bracket was attached so the tooth could be properly positioned.

As soon as the molars were moved distally and a Class I molar relationship was achieved the patient was fully bonded with an edgewise Bidimensional technique.

To maintain the Class I molar position, the cervical headgear was continued 10 to 14 hours/day. While the molar position was stabilized, the premolars drifted distally into a Class I occlusion and the canines were retracted using light forces. Incisor retraction was achieved with Class I elastics and sliding mechanics.

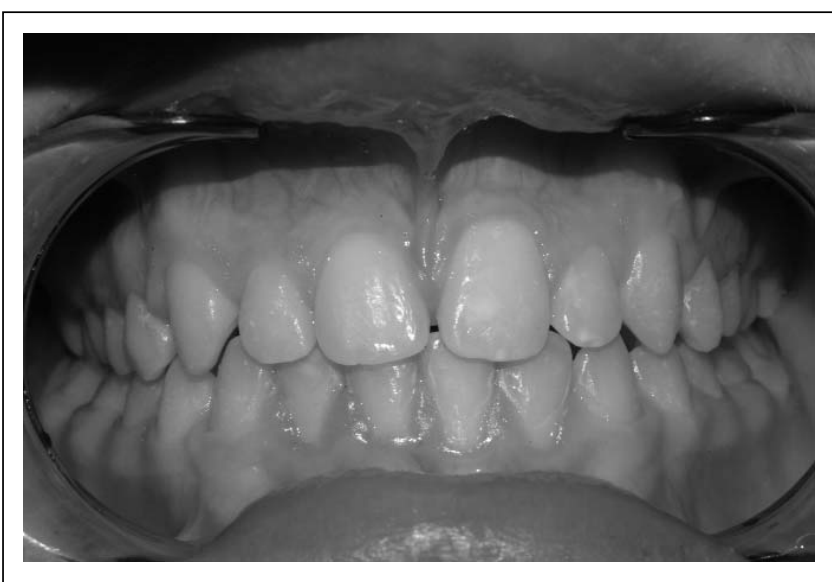

Figure 5. Intraoral frontal view after orthodontic treatment

The patient was cooperative and the appliances were removed 24 months after initiation of the treatment. (Figure 5) Retention was accomplished with removable acrylic retainers. The patient was instructed to wear the retainers only at night. He is currently on routine patient recall.

\section{TREATMENT PROGRESS}

Panoramic radiograph evaluation, carried out at the end of the treatment, demonstrated the root angulation to be about 35 degrees. (Figure 6a).

Radiographically, in fact, the crown of the maxillary left central incisor was into proper alignment; while the newly positioned tooth revealed no proper root alignment, as result of the root dilaceration, with no appar-
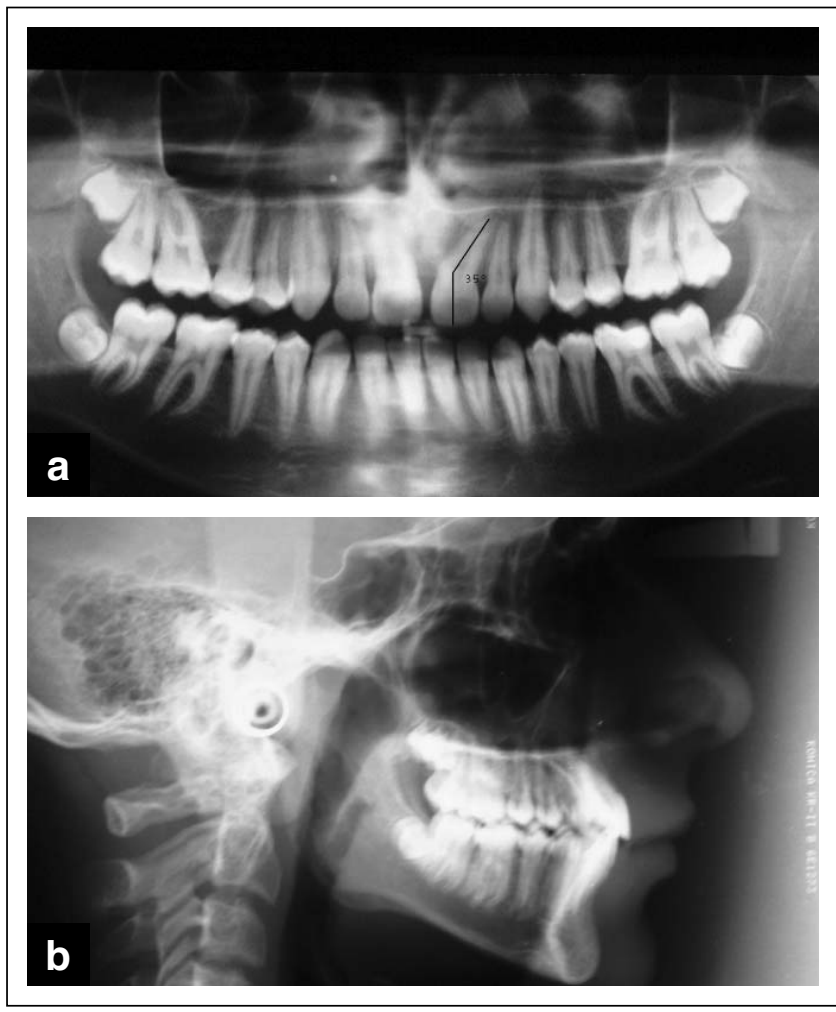

Figure 6. Radiographic views after orthodontic treatment: a.: Panoramic view; b.: Lateral cephalometric radiographic view 
ent resorption. The bony height is satisfactory radiographically.

Cephalometrically, a skeletal class I (ANB T0:4', $\left.\mathrm{T} 1: 1^{\circ}\right)$ was achieved, reflecting a decrease in SNA angle (SNA T0:83 ${ }^{\circ}, \mathrm{T}^{\circ}: 81^{\circ}$ ) (Figure 6b) (Tab. 1).

An ideal overbite (T0:4mm, T1:2 mm) and overjet (T0:4.5mm, T1:2 mm) was established and a class I molar and canine relationship was exhibited. Good intercuspation was achieved and midlines were coincident.

The impacted maxillary central incisor was uncovered surgically and moved favorable into place ortodontically.

The final appearance of the tooth was esthetically pleasing, with gingival margins at the same level with similar clinical crowns sizes. The tooth responded well to vitality and did not show abnormalities in crown shape. Periodontally a band of labial keratinized gingiva measuring $4 \mathrm{~mm}$ was present, and pocket depth ranged from 1 to $2 \mathrm{~mm}$.

\section{DISCUSSION}

Maxillary central incisor impaction occurs infrequently; It includes various local causes, such as the presence of odontomas, supernumerary teeth and loss of space. ${ }^{7.8}$ In our patient, impaction was probably secondary to traumatic injury at age 4 which resulted in a root dilaceration.

When an injury to a primary tooth occurs at young age diagnostic tests should be performed as soon as possible; in fact, earlier treatment usually bears better results. ${ }^{9}$

Appropriate radiographs and a thorough history are necessary components for diagnosis, treatment and follow up care. Informing the parents of the possible sequelae to the permanent successor is a vital part of the treatment too. The patient should have follow up appointments and appropriate periodic radiographs of the traumatized area. ${ }^{10}$

In this case the maxillary left central primary incisor was extracted too late because the patient did not seek orthodontic treatment until age 12.

Most authorities agree that there are two possible causes of dilaceration. The most widely accepted is trauma; injury to primary predecessor could result in dilaceration of the developing succedaneous permanent tooth. Subsequently the calcified portion of the permanent tooth germ is formed at an angle. Traumatic injuries cannot account for all causes of dilaceration especially those of primary teeth. An idiopatic developmental disturbance is proposed as another possible cause in cases that have no clear evidence of trauma. ${ }^{2,11}$

The degree and level of dilaceration, tooth's vertical position and tooth's maturity are factors determining the success rate of orthodontic-surgical management of the impacted tooth. A dilacerated tooth with a more occlusal position in the alveolus, an obtuse crown- root angulation and an incomplete root formation would have a better prognosis for orthodontic traction. ${ }^{1}$

In our patient dilaceration was at the level of the root's apical third and the root formation was incomplete and usually these two factors improve the prognosis. However it was necessary to inform the parents of the possible risks.

The current treatment modality of a dilacerated incisor involves, instead of extraction of the dilacerated tooth, surgical crown exposure with the placement of an auxiliary, followed by orthodontic repositioning of the tooth. In fact several reports recently have successfully treated dilacerated teeth with this approach. ${ }^{1,4,12,13}$ Consequently, just as the present case revealed, the dilaceration of the root would not pose a great obstacle if the case is carefully planned and alternatives are contemplated.

Several techniques are available for managing impacted incisors. ${ }^{8}$ In some cases conservative management is the better solution, but most patients will require surgical or orthodontic manipulation with their possible sequelae including inadequate margin tissue and excessive bone loss. ${ }^{5,8}$ In this case, in order to avoid these sequelae and to minimize the trauma of surgery, the tissues around the unerupted tooth were not removed. The surgical flap was repositioned and sutured in place according to what is called "closed eruption technique"; only the ligature wire attached to the button on the impacted tooth was exposed into the oral cavity. This technique induces a more natural tooth eruption of the impacted tooth rather than conventional design of the apically positioned flap. ${ }^{5,14-16}$ Vermette et al compared, in fact, these two techniques and found that the apically positioned flap technique had more negative effects such as increased crown length and gingival scars than the closed eruption one. ${ }^{16}$

Moreover the delayed eruption of a maxillary incisor in a child poses a disturbing esthetic dilemma to parents by virtue of its location. The eruption of the impacted tooth gives to the patient confidence to smile and enhances self- esteem, which is a critical problem in early life.

\section{CONCLUSION}

Surgical exposure and orthodontic traction is the treatment most often used for impacted dilacerated incisors. This technique in fact can lead to suitable results at the periodontal, occlusal and esthetic levels at an early stage and more definitively than with other treatment options. However, long-term monitoring of the stability and periodontal health of the dilacerated incisor is very important after orthodontic traction. 


\section{REFERENCES}

1. Chew MT, Ong M M-A Orthodontic-surgical management of an impacted dilacerated maxillary central incisor: a clinical case report. Pediatr Dent. 26:341-44, 2004.

2. Yeung KH, Cheung RCT, Tsang MMH. Compound odontoma associated with an unerupted and dilacerated maxillary primary central incisor in a young patient. Inter $\mathrm{J}$ Pediatr Dent. 13:208-12, 2003.

3. Boyd RL. Clinical assessment of injuries in orthodontic movement of impacted teeth. I. Methods of attachment. Am J Orthod Dentofac Orthop. 82: 478-86, 1982

4. Lin Y-TJ. Treatment of an impacted dilacerated maxillary central incisor. Am J Orthod Dentofac Orthop. 115:406-09, 1999.

5. Kajiama K, Kai H. esthetic management of an unerupted maxillary central incisor with a closed eruption technique. Am J Orthod Dentofac Orthop 118:224-28, 2000.

6. Tsai T-P. Surgical repositioning of an impacted dilacerated incisor in mixed dentition. JADA 133:61-66, 2002.

7. Langowska-Adamcżyk H, Karmańska B. Similar location of impacted and supernumerary teeth in monozygotic twins: a report of 2 cases. Am J Orthod Dentofac Orthop. 119:67-70, 2001.

8. Macìas E, de Carlos F, Cobo J. Posttraumatic impaction of both maxillary central incisors. Am J Orthod Dentofac Orthop 124:331-38, 2003.
9. Munns D, Surry AHA. Unerupted incisors. Br J Orthod. 8:39-42, 1981.

10. Montalvo-Polk A, Kittle PE. Impaction and malformation of a maxillary central incisor: sequelae of trauma. J Dent Child. 38 :29-32, 1993.

11. Kilpatrick NM, Hardman PJ, Welbury RR. Dilaceration of a primary tooth. Inter J Ped Dent. 1:151-53, 1991.

12. Crawford LB. Impacted maxillary central incisor in mixed dentition treatment. Am J Orthod Dentofac Orthop. 112:1-7, 1997.

13. Uematsu S, Uematsu T, Furusawa K, Deguchi T, Kurihara S. Orthodontic treatment of an impacted dilacerated maxillary central incisor combined with surgical exposure and apicoectomy. Angle Orthod. 74:132-36, 2004.

14. Becker A. Early treatment for impacted maxillary incisor. Am J Orthod Dentofac Orthop. 121:586-87, 2002.

15. Becker A, Brin I, Ben-Bassat Y, Zilberman Y, Chausu S. Closederuption surgical technique for impacted maxillary incisors: A postorthodontic periodontal evaluation. Am J Orthod Dentofac Orthop.122:9-14, 2002.

16. Vermette ME, Kokich VG, Kennedy DB. Uncovering labially impacted teeth: apically positioned flap and closed eruption techniques. Angle Orthod. 65:23-32, 1995. 
Orthodontic treatment of an impacted dilacerated maxillary incisor: A case report

\section{Educating Pediatricians on Children Oral Health: Past, Present and Future: Kroll DM. Pediatrics 113:e487-e492. 1390, 2004}

www.pediatrics.org/cgi/content/full113/5/e487

This article reviews pediatrician experiences in oral health training at the undergraduate, graduate and continuing education courses, looking at current medical guidelines and programs.

Results demonstrated that including oral health in their programs is not a prevalent phenomenon is most medical and residency programs. Pediatricians, when surveyed suggest that their oral health education is inadequate.

The author concludes that a greater effort should be placed and cooperation between many organizations and a genuine commitment are necessary to improve the quality of pediatric education and medical care for children. 